\title{
PENILAIAN PROYEK BERPENDEKATAN VISUAL, AUDITORI, DAN KINESTHETIK DENGAN PRODUK STORYBOARD DAN PENERAPANNYA PADA SISWA SMA
}

\author{
Wilis Okti Pamungkas, Nanik Wijayati, Sudarmin \\ Program Studi Pendidikan Kimia FMIPA \\ Universitas Negeri Semarang, Indonesia 50299 \\ E-mail: wilisokti@gmail.com
}

\begin{abstract}
Authentic assessment is assessment instrument that assess the learning process and learning outcomes of students. Authentic assessment instrument which developed in this research is project assessment instrument with storyboard product. This study aims to develop project assessment instruments which are valid, reliable and effective to be used for all of the students. The research method used is the modified 4-D model. This research implemented in grade class XI of SMA N 10 Semarang and subjects of research is students in class XI with IPA concentration. The results of research showed that project assessment instruments valid, reliable, and proper to used for assessing learning process and learning outcomes. Project assessment instrument effective used in learning, because the vmean of project assessment and learning outcomes all of students gained a value with the minimum criteria of good, also there is an ascendant of $\mathrm{N}$-gain with high category for students visual, student auditory, and student kinesthetic. Thus it can be concluded that the developed assessment instruments is valid, reliable, and effective.

Keywords: Project Assessment; Storyboard; Visual, Auditory, and Kinesthetik Approach
\end{abstract}

Belajar adalah salah satu kegiatan yang selalu dilakukan setiap saat baik disadari ataupun tidak. Proses belajar yang dirancang untuk tujuan tertentu adalah pembelajaran. Kualitas pembelajaran dapat dilihat dari segi proses dan segi hasil. Dari segi proses, pembelajaran dikatakan berhasil dan berkualitas apabila seluruh siswa atau setidaknya sebagian besar siswa terlibat secara aktif dalam proses pembelajaran. Sedangkan dari segi hasil, proses pembelajaran dikatakan berhasil apabila terjadi perubahan perilaku yang positif pada diri semua siswa
(Mulyasa, 2013). Dalam sebuah kelas, terdapat beberapa cara terbaik bagi siswa untuk belajar yang sering disebut dengan gaya belajar. Gaya belajar siswa dapat dibedakan menjadi gaya belajar visual, auditori dan kinesthetik (Porter \& Hernacki, 2008). Karena dalam satu kelas terdapat berbagai macam gaya belajar, maka metode pembelajaran yang baik adalah metode yang dapat memudahkan siswa visual, siswa auditori, dan siswa kinesthetik belajar secara aktif baik di dalam maupun di luar kelas. 
Hasil observasi yang dilakukan di SMA N 10 Semarang pada bulan agustus sampai dengan bulan oktober 2015 menunjukkan bahwa pembelajaran kimia yang diterapkan di dalam kelas menggunakan metode yang yang sama untuk setiap materi. Metode yang digunakan adalah metode diskusi dan metode ceramah dengan mengkaji berbagai macam soal untuk memperdalam materi yang sedang dipelajari. Pembelajaran yang menggunakan metode demikian akan menguntungkan siswa yang memang memiliki kelebihan untuk belajar dengan cara mendengar. Siswa visual dan siswa kinesthetik yang tidak memiliki kelebihan tersebut akan merasa kesulitan untuk menyerap materi baru yang sedang dibahas oleh guru dan teman mereka. Hal inilah yang menyebabkan sebagian besar siswa menjadi pasif dan kurang tertarik untuk mempelajari kimia. Siswa visual dan siswa kinesthhetik akan aktif dalam pembelajaran jika diberikan nilai pada aktivitas yang dilakukannya, sehingga diperlukan sebuah penilaian proses yang dapat menunjang kualitas pembelajaran kimia. Salah satu penilaian yang menekankan pada penilaian proses adalah penilaian otentik. Penilaian proses perlu dilakukan agar siswa visual, siswa auditori, maupun siswa kinesthetik aktif dalam pembelajaran.

Penilaian otentik berbasis proyek atau yang biasa disebut dengan penilaian proyek merupakan salah satu jenis penilaian yang mengakomodasi perbedaan gaya belajar siswa dan digunakan untuk menilai proses disamping produk hasil proyek sebagai sumber penilaian. Penilaian proyek menekankan pada kemampuan merencanakan, mengorganisasikan investigasi, dan kerjasama dalam tim (Wijayanti, 2014). Penilaian yang menuntut siswa untuk belajar bersama dalam sebuah tim akan memunculkan kekuatan dan kemampuan masingmasing siswa untuk menunjukkan performanya selama proses pembelajaran (Kyprianidou et al., 2012).

Penilaian proyek menggunakan berbagai cara dan berbagai instrumen untuk mengetahui perkembangan siswa selama proses pembelajaran (Kunandar, 2013). Variasi cara penilaian yang terdapat dalam penilaian proyek akan membuat siswa aktif belajar karena penilaian dilakukan dengan berbagai teknik yang dirancang untuk memudahkan siswa baik siswa visual, siswa auditori, maupun siswa kinesthetik dalam mengaktualisasikan pengetahuannya melalui sebuah proyek. Produk hasil proyek dapat menggunakan alternatif lain seperti pembuatan storyboard. Selain dapat digunakan untuk melihat konstruksi pengetahuan yang dimiliki siswa, media ini juga dapat dijadikan tempat untuk mengeluarkan ekspresi dan kreativitas masing-masing siswa.

Instrumen penilaian otentik yang dikembangkan dalam penelitian ini adalah instrumen penilaian proyek yang didesain untuk mengaktifkan siswa. Keaktifan siswa dalam pembelajaran dilihat dari kelengkapan tugas yang dikerjakan oleh siswa dan aktivitas siswa selama mengikuti proses pembelajaran. Selain itu, instrumen penilaian proyek pada materi titrasi asam basa juga akan melatih kemandirian siswa dalam mengerjakan proyek melalui sebuah investigasi yang ditugaskan kepada 
siswa secara berkelompok. Tujuan penelitian ini adalah mengembangkan instrumen penilaian proyek yang valid, reliabel, dan efektif digunakan dalam pembelajaran pada materi titrasi asam basa.

\section{METODE}

Penelitian pengembangan instrumen penilaian otentik ini menggunakan metode Research and Development model $4 D$ modifikasi yang terdiri dari tahap define, design, dan develop, sedangkan tahap disseminate tidak dilakukan. Instrumen yang dikembangkan adalah instrumen penilaian proyek. Subjek penelitian ini adalah siswa kelas XI konsentrasi IPA SMA N 10 Semarang.

Prosedur

penelitian

pengembangan instrumen penilaian proyek diawali dengan tahap define yang meliputi identifikasi potensi dan masalah, serta pengumpulan data. Data yang diperoleh kemudian dijadikan kajian literatur dalam mendesain instrumen penilaian proyek yang ingin dikembangkan (tahap design). Desain instrumen penilaian proyek yang telah dirancang selanjutnya disempurnakan dalam tahap develop yang terdiri dari validasi ahli, revisi desain, uji coba skala kecil, revisi, uji coba skala besar, dan revisi instrumen penilaian. Ahli dalam penelitian ini tiga orang dosen Jurusan Kimia Universitas Negeri Semarang.

Teknik pengumpulan data melalui teknik tes, angket, dan observasi. Data yang dikumpulkan dalam penelitian ini adalah: (1) lembar validasi instrumen penilaian proyek, instrumen penilaian storyboard dan soal titrasi asam basa untuk menilai aspek kognitif, instrumen penilaian afektif serta instrumen penilaian psikomotor; (2) nilai proyek, nilai storyboard, nilai ulangan, nilai afektif, dan nilai psikomotor. Sedangkan analisis data yang dilakukan dalam penelitian ini meliputi: (1) analisis validitas dan reliabilitas semua instrumen, yang terdiri dari instrumen penilaian proyek, instrumen penilaian storyboard, soal titrasi asam basa, instrumen penilaian afektif dan instrumen penilaian psikomotor; (2) analisis nilai proyek, nilai storyboard, nilai ulangan, nilai afektif dan nilai psikomotor.

\section{HASIL DAN PEMBAHASAN}

Penelitian pengembangan instrumen ini diawali dengan tahap define, yaitu observasi dan wawancara yang menunjukkan bahwa sebagian besar siswa pasif selama proses pembelajaran. Kajian literatur menunjukkan bahwa penerapan penilaian proyek yang meliputi penilaian proses dan hasil belajar akan meningkatkan partisipasi semua siswa, sehingga kualitas proses dan hasil belajar siswa meningkat.

Instrumen penilaian proyek hasil desain terdiri dari tiga tahap penilaian yaitu penilaian perencanaan, penilaian pelaksanaan proyek, dan penilaian pembuatan produk. Instrumen penilaian proyek yang telah dirancang, selanjutnya memasuki tahap develop. Tahap ini terdiri dari validasi ahli, uji coba skala kecil, dan uji coba skala besar. Validasi ahli bertujuan untuk mendapatkan saran dan perbaikan yang sesuai untuk memperbaiki produk sebelum tahap uji coba. 
Tabel 1. Hasil validasi instrumen penilaian proyek oleh ahli.

\begin{tabular}{|c|c|c|c|c|c|c|}
\hline \multirow{2}{*}{ No } & \multirow{2}{*}{ Aspek Validasi } & \multicolumn{3}{|c|}{ Validator } & \multirow{2}{*}{$\begin{array}{l}\text { Rata- } \\
\text { rata }\end{array}$} & \multirow{2}{*}{ Kriteria } \\
\hline & & 1 & 2 & 3 & & \\
\hline 1 & Bahasa & 3 & 3 & 3 & 3 & Cukup Valid \\
\hline 2 & Susunan kalimat & 3 & 3 & 3 & 3 & Cukup Valid \\
\hline 3 & $\begin{array}{l}\text { Kelengkapan format instrumen } \\
\text { penilaian proyek }\end{array}$ & 4 & 4 & 4 & 4 & Valid \\
\hline 4 & $\begin{array}{l}\text { Kesesuaian penilaian dengan } \\
\text { standar kompetensi }\end{array}$ & 4 & 3 & 3 & 3,33 & Vaild \\
\hline 5 & $\begin{array}{l}\text { Indikator instrumen penilaian } \\
\text { proyek }\end{array}$ & 4 & 3 & 4 & 3,67 & Valid \\
\hline \multirow[t]{2}{*}{6} & Aspek otentik & 4 & 3 & 3 & 3,33 & Valid \\
\hline & \multicolumn{4}{|c|}{ Rerata Penilaian Ahli (va) } & 3,38 & Valid \\
\hline
\end{tabular}

Instrumen yang divalidasi ahli terdiri dari instrumen penilaian proyek dan instrumen penilaian hasil belajar. Hasil validasi instrumen penilaian proyek oleh para ahli disajikan pada Tabel 1. Hasil validasi yang dilakukan oleh tiga validator menunjukkan bahwa instrumen penilaian proyek yang dikembangkan valid, karena rerata hasil penilaian ahli (va) sebesar 3,38 dengan kriteria valid (Safitri, 2015). Saran dan masukan yang diberikan oleh ahli menjadi bahan revisi dan bahan pertimbangan untuk perbaikan agar instrumen yang dikembangkan menjadi lebih baik sebelum digunakan dalam uji coba skala kecil (Lestari et al., 2015).

Instrumen penilaian hasil belajar yang terdiri dari soal titrasi asam basa, instrumen penilaian storyboard, instrumen penilaian afektif, dan instrumen penilaian psikomotor juga divalidasi ahli. Validasi instrumen penilaian hasil belajar oleh para ahli disajikan pada Tabel 2. Berdasarkan data pada Tabel 2, semua instrumen penilaian hasil belajar valid menurut ahli, sehingga dapat digunakan pada tahap uji coba.

Tabel 2. Validasi instrumen penilaian hasil belajar oleh ahli.

\begin{tabular}{lcccccc}
\hline \multirow{2}{*}{ Instrumen yang divalidasi } & \multicolumn{3}{c}{ Validator } & \multirow{2}{*}{ Rerata (va) } & \multirow{2}{*}{ Kriteria } \\
\cline { 2 - 4 } & $\mathbf{1}$ & $\mathbf{2}$ & $\mathbf{3}$ & & \\
\hline Soal Titrasi Asam Basa & 3,2 & 3,4 & 3,4 & 3,33 & Valid \\
Instrumen penilaian storyboard & 3,25 & 3,5 & 3,25 & 3,33 & Valid \\
Instrumen penilaian afektif & 3,8 & 3,6 & 3,8 & 3,73 & Valid \\
Instrumen penilaian psikomotor & 3,25 & 3,5 & 3,5 & 3,42 & Valid \\
\hline
\end{tabular}

Instrumen penilaian otentik yang sudah valid kemudian memasuki tahap uji coba skala kecil. Uji ini melibatkan 10 orang siswa kelas XI IPA SMAN 10 Semarang dan dilakukan untuk mengetahui keterlaksanaan penggunaan instrumen penilaian proyek pada pembelajaran kimia. Pelaksanaan uji coba skala kecil memiliki beberapa hambatan diantaranya yaitu format 'Lembar Pencarian Informasi' kurang 
mendukung proses perencanaan proyek. Hambatan ini menjadi catatan perbaikan saat melaksanakan uji coba skala besar.

Tabel 3. Rekap hasil reliabilitas instrument.

\begin{tabular}{lcc}
\hline \multicolumn{1}{c}{ Instrumen } & Pengujian & $\begin{array}{c}\text { Koefisien Reliabilitas } \\
\left(r_{11}\right)\end{array}$ \\
\hline Instrumen penilaian proyek & Alpha Cronbach & 0,72 \\
Soal titrasi asam basa & Alpha Cronbach & 0,80 \\
Instrumen penilaian afektif & KR-20 & 0,89 \\
Instrumen penilaian psikomotor & Inter Rater Reability & 0,62 \\
\hline
\end{tabular}

Tahap selanjutnya adalah uji coba skala besar yang dilakukan untuk mengetahui reliabilitas instrumen yang digunakan. Instrumen yang dikembangkan sudah reliabel, karena memiliki nilai koefisien reliabilitas lebih besar dari 0,6 (Safitri, 2015). Rekap hasil reliabilitas instrumen disajikan pada Tabel 3.

Pada penelitian ini selain validitas dan reliabilitas instrumen, juga untuk mengetahui keefektifan penggunaan instrumen penilaian proyek terhadap semua siswa baik siswa visual, siswa auditori, dan kinesthetik. Uji keefektifan instrumen penilaian proyek dilakukan terhadap 33 siswa kelas XI IPA. Keefektifan penggunaan instrumen penilaian proyek dilihat dari hasil penilaian proyek dan hasil belajar siswa. Hasil penilaian proyek disajikan pada Gambar 1.

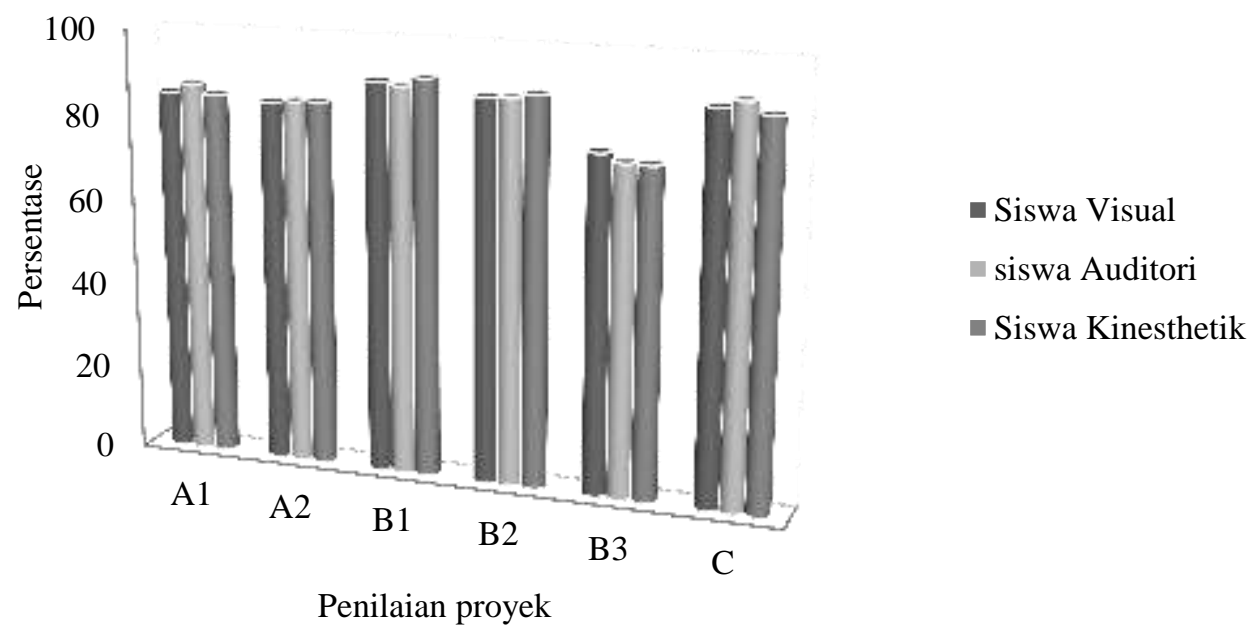

Keterangan:

A1 : Pencarian Informasi

B1 : Persiapan Praktikum

A2 : Perencanaan Kegiatan Proyek

B3 : Aktivitas Selesai Praktikum

B2 : Aktivitas Selama Praktikum

C : Pembuatan Produk

Gambar 1. Hasil penilaian proyek. 
Data pada Gambar 1 menunjukkan bahwa ketercapaian tiap aspek pada penilaian proyek minimal pada kriteria baik yaitu diatas $70 \%$. Perolehan nilai tersebut mengindikasikan bahwa semua siswa aktif pada semua tahapan pembelajaran. Keaktifan siswa selama proses pembelajaran ini terjadi karena semua siswa tertarik mengikuti proses pembelajaran. Penerapan penilaian proyek yang menyenangkan akan membuat siswa menikmati aktivitasnya dan termotivasi dengan pembelajaran yang dilakukan (Andreea \& Stancuna, 2014). Selain itu, penggunaan penilaian proyek akan meningkatkan ketertarikan siswa untuk mendalami materi pembelajaran (Holm, 2011). Penggunaan penilaian proyek juga memberikan kesempatan kepada siswa untuk melaksanakan tugas yang menarik bagi siswa, bermanfaat, dan relevan dengan kehidupan siswa (Wijayanti, 2014).

Penilaian proyek yang diterapkan dalam pembelajaran akan menyebabkan semua siswa aktif selama pembelajaran baik siswa visual, siswa auditori, maupun siswa kinesthetik. Selama perencanaan proyek, siswa visual dituntut untuk mencari informasi secara mandiri dari berbagai sumber yang disukainya baik dari buku, melihat video atau sumber lainnya mengenai penentuan kadar asam asetat dalam cuka. Siswa visual juga aktif selama proses pembelajaran karena siswa tertarik mempelajari titrasi asam basa dengan cara mengamati langsung prosesnya pada saat pelaksanaan proyek. Keaktifan siswa visual juga disebabkan oleh pembelajaran yang menarik bagi dirinya dengan adanya tugas pembuatan storyboard yang dapat digunakan sebagai media untuk mengekspresikan pengetahuannya melalui sebuah gambar. Hal ini juga sesuai dengan penelitian Sari (2014) yang mengemukakan bahwa siswa visual akan termotivasi mengikuti pembelajaran dengan memberikan tugas untuk menggambarkan informasi, membuat diagram, simbol dan gambar berwarna.

Selama proses pembelajaran yaitu pada saat perencanaan proyek, siswa auditori dituntut untuk mencari informasi secara mandiri dari berbagai sumber yang disukainya baik dari penjelasan guru, hasil diskusi atau sumber lainnya. Siswa auditori juga aktif selama proses pembelajaran karena siswa antusias mendiskusikan hasil proyek yang dikerjakan bersama dengan teman satu kelompok mengenai penentuan kadar asam asetat dalam cuka. Keaktifan siswa auditori juga disebabkan oleh pembelajaran yang menarik bagi dirinya dengan adanya tugas pembuatan laporan yang diselesaikan secara berkelompok, sehingga memungkinkan dirinya untuk bertukar pikiran mengenai proyek yang telah dilakukan. Leopold (2012) berpendapat bahwa siswa auditori menyukai kegiatan diskusi, belajar dengan cara mendengarkan sebuah cerita dan memahami konsep lebih jelas apabila dijelaskan terlebih dahulu dibandingkan dengan didahului membaca sebuah teks.

Selama proses pembelajaran yaitu pada saat perencanaan proyek, siswa kinesthetik dituntut untuk mencari informasi secara mandiri dari berbagai sumber yang disukainya baik dari penjelasan guru melalui sebuah demonstrasi, penjelasan 
langsung dari guru mengenai aplikasi langsung titrasi asam basa dalam kehidupan sehari-hari atau sumber lainnya mengenai penentuan kadar asam asetat dalam cuka. Siswa kinesthetik juga aktif selama proses pembelajaran karena siswa tertarik mempelajari titrasi asam basa dengan langsung mempraktikkannya selama pelaksanaan proyek. Keaktifan siswa kinesthetik juga disebabkan oleh tugas yang diberikan padanya yaitu membuat storyboard. Media ini dapat digunakan untuk mengkonstruksi pengetahuannya melalui sebuah visualisasi gambar mengenai langkahlangkah menentukan kadar asam asetat dalam cuka yang telah dilakukannya. Sari (2014) dalam penelitiannya mengemukakan bahwa siswa kinesthetik akan tertarik mengikuti pembelajaran jika diberikan sebuah tugas berupa proyek terapan. Siswa kinesthetik juga akan antusias saat proses pembelajaran apabila guru memperagakan konsep sambil memberikan kesempatan kepada siswa untuk mempelajarinya langkah demi langkah, menciptakan simulasi konsep agar siswa mengalaminya, dan membuat peta pikiran dengan melibatkan aktivitas fisik.

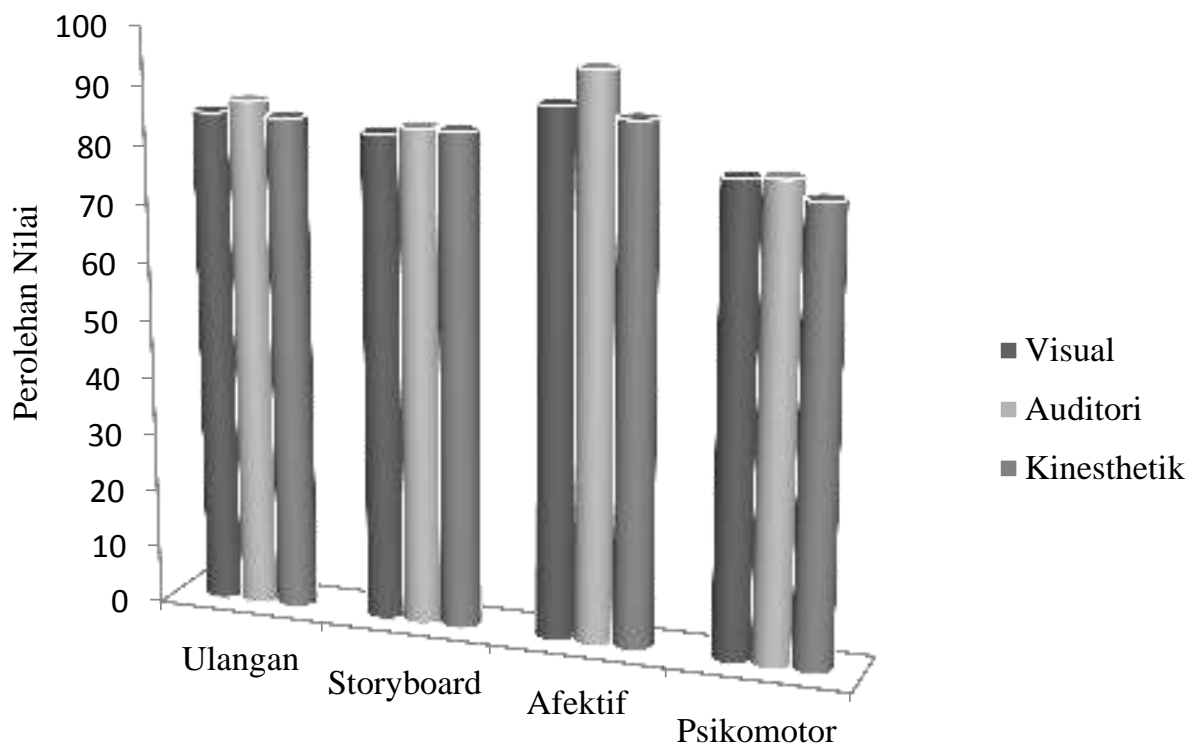

Hasil Penilaian

Gambar 2. Penilaian hasil belajar siswa.

Hasil belajar siswa dilihat dari nilai ulangan, nilai storyboard, nilai afektif, dan nilai psikomotor. Berdasarkan data yang terdapat pada Gambar 2, siswa visual, siswa auditori, dan siswa kinesthetik mendapatkan nilai minimal dengan kriteria baik atau mendapatkan nilai lebih besar dari 70 untuk masingmasing penilaian storyboard, penilaian afektif, penilaian psikomotor dan ulangan. Ketercapaian hasil belajar ini disebabkan oleh keaktifan semua siswa selama mengikuti proses pembelajaran dengan menerapkan 
instrumen penilaian proyek. Hal ini juga sesuai dengan penelitian yang dilakukan oleh Amalina et al (2013) (Amalina et al., 2013) yang menunjukkan bahwa penggunaan media belajar dan variasi pembelajaran yang melibatkan partisipasi aktif siswa dalam kegiatan AMBAK (Apa Manfaatnya Bagiku), praktikum, diskusi, tanya jawab, membuat molymood, membaca komik hidrokarbon, dan mengerjakan soal evaluasi akan berpengaruh terhadap hasil belajar siswa visual, siswa auditori, dan siswa kinesthetik.

Pemahaman konsep siswa mengenai titrasi asam basa cukup tinggi berdasarkan hasil ulangan yang diperoleh minimal pada kriteria baik untuk semua siswa. Selain pemahaman konsep siswa, peningkatan pemahaman konsep juga untuk mengetahui keefektifan penggunaan instrumen penilaian proyek dalam pembelajaran yang dilihat dari hasil pre-test dan posttest. Peningkatan penguasaan konsep dianalisis dengan menggunakan nilai $\mathrm{N}$-gain. Hasil peningkatan nilai pretest dan post-test disajikan pada Tabel 4. Pada Tabel 4 menunjukkan bahwa peningkatan nilai $\mathrm{N}$-gain semua siswa berada pada kategori tinggi, artinya siswa visual, siswa auditori, dan siswa kinesthetik sudah mengalami proses belajar dengan baik dan benar. Dengan demikian, pembelajaran yang menerapkan penilaian proyek dapat meningkatkan pemahaman konsep siswa.

Peningkatan nilai pre-test dan post-test siswa visual berada pada kategori tinggi, artinya ada peningkatan pengetahuan mengenai titrasi asam basa sebelum dan sesudah mengikuti proses pembelajaran. Hal ini terjadi karena selama pembelajaran, siswa dapat melihat proses titrasi baik melalui demonstrasi, maupun mengamati proses titrasi yang dilakukannya. Disamping itu, sebelum pelaksanaan proyek siswa sudah membuat diagram alir terlebih dahulu sehingga pengetahuannya akan titrasi telah tertuang dalam sebuah diagram yang akan memudahkan siswa visual memahami prosesnya. Pemahaman siswa mengenai titrasi asam basa dikarenakan siswa visual belajar dengan melihat secara langsung proses titrasi. Inayati et al., (2012) juga mengemukakan bahwa siswa visual yang belajar langsung dengan cara mengamati melalui sebuah praktikum akan berdampak positif pada hasil belajar siswa tersebut.

Tabel 4. Hasil peningkatan nilai pre-test dan nilai post-test.

\begin{tabular}{ccccc}
\hline \multirow{2}{*}{ Siswa } & \multicolumn{2}{c}{ Nilai } & \multirow{2}{*}{ N-gain } & \multirow{2}{*}{ Kategori } \\
\cline { 2 - 3 } & Pre-Test & Post-test & & Tinggi \\
Visual & 45,94 & 85,47 & 0,73 & Tinggi \\
Auditori & 42,95 & 87,69 & 0,78 & Tinggi \\
Kinesthetik & 40,68 & 85,23 & 0,75 & \\
\hline
\end{tabular}

Peningkatan nilai pre-test dan post-test siswa auditori berada pada kategori tinggi. Peningkatan ini terjadi karena selama pembelajaran, 
siswa dengan seksama mendengarkan penjelasan guru, aktif saat berdiskusi dan mengerjakan latihan soal yang diberikan guru. Selain itu, siswa auditori aktif mendiskusikan data hasil titrasi yang dilakukannya bersama teman satu kelompok untuk menentukan kadar asam asetat dalam cuka. Pemahaman konsep siswa auditori yang baik disebabkan pembelajaran dan penilaian yang sesuai dengan cara belajar siswa auditori, yaitu belajar dengan mendengar penjelasan guru, mengeluarkan pendapat saat berdiskusi, dan aktif dalam kelompok saat melakukan proses titrasi. Hasil ini juga sesuai dengan hasil penelitian Inayati et al., (2012) yang mengemukakan bahwa siswa auditori belajar dengan efektif melalui diskusi, mendengarkan penjelasan guru dan aktif mendiskusikan data hasil praktikum yang telah dilakukannya.
Peningkatan nilai pre-test dan post-test siswa kinesthetik berada pada kategori tinggi. Peningkatan ini terjadi karena selama pembelajaran, siswa aktif bertanya kepada guru dan aktif dalam melakukan proses titrasi. Pemahaman siswa mengenai titrasi asam basa dikarenakan siswa kinesthetik belajar dengan aktif baik saat praktikum maupun sebelum praktikum. Selain itu pembelajaran yang menghubungkan materi dengan masalah nyata yang ada di sekelilingnya akan memudahkan siswa kinesthetik untuk memahami materi. Pemahaman konsep siswa kinesthetik yang baik disebabkan pembelajaran dan penilaian yang sesuai dengan cara belajar siswa kinesthetik, yaitu belajar dengan cara terlibat langsung dalam proses titrasi sehingga akan lebih memudahkan siswa kinesthetik memahami materi titrasi asam basa (Jagantara et al., 2014).



Gambar 3. Contoh storyboard hasil proyek siswa 
Storyboard merupakan produk hasil proyek yang digunakan untuk mengetahui pemahaman siswa terhadap proyek yang telah dilakukan, yaitu menentukan kadar asam asetat dalam cuka melalui proses titrasi. Gambar 3 merupakan salah satu contoh storyboard hasil proyek siswa. Rerata hasil penilaian storyboard siswa visual, siswa auditori, dan siswa kinesthetik minimal pada kriteria baik, artinya semua siswa memahami pelaksanaan proyek yang dilakukan. Hal ini juga sesuai dengan penelitian Schnittka et al., (2015) yang mengemukakan bahwa penggunaan storyboard dalam pembelajaran akan menumbuhkan rasa percaya diri siswa untuk mengkomunikasikan apa yang mereka ketahui dan pahami. Selain itu, penggunaan storyboard sebagai produk atau hasil karya dalam pembelajaran juga akan menyediakan pengalaman yang bermakna untuk siswa (Lillyman et al., 2011).

Kompetensi afektif berkaitan dengan minat dan sikap. Antara sikap dan pengetahuan saling mempengaruhi, siswa yang memiliki minat dalam suatu pelajaran akan mencapai hasil pembelajaran yang optimal (Kunandar, 2013). Berdasarkan Gambar 2, siswa cenderung memiliki nilai afektif yang tinggi disamping pemahaman konsep yang baik. Nilai afektif siswa visual, siswa auditori, dan siswa kinesthetik berada pada kriteria minimal baik. Nilai afektif yang tinggi selama mengikuti pembelajaran berbasis proyek ini juga sesuai dengan penelitian yang dilakukan oleh Mancas (2011) bahwa penggunaan penilaian dan pembelajaran berbasis proyek akan merubah perilaku siswa dan membuat mereka lebih bertanggungjawab pada proyek yeng diberikan. Penggunaan penilaian berbasis proyek akan meningkatkan percaya diri dan rasa ingin tahu siswa akan materi pembelajaran.

Psikomotor berhubungan dengan hasil belajar yang pencapaiannya melalui keterampilan sebagai hasil tercapainya kompetensi pengetahuan (kognitif). Hal ini berarti kompetensi keterampilan itu sebagai implikasi dari tercapainya kompetensi pengetahuan siswa (Kunandar, 2013). Berdasarkan data pada Gambar 2, nilai psikomotor siswa visual, siswa auditori, dan siswa kinesthetik berada pada kriteria minimal baik. Hasil capaian kompetensi psikomotor siswa yang baik dikarenakan pelaksanaan proyek yang menekankan pada kerjasama tim. Setiap kelompok yang terdiri dari lebih dari satu jenis gaya belajar siswa memiliki dampak yang positif terhadap kompetensi psikomotor siswa. Hal ini juga sesuai dengan penelitian yang dilakukan oleh Kyprianidou et al., (2012) bahwa satu kelompok yang terdiri dari berbagai gaya belajar akan berdampak pada psikomotor siswa seperti adanya manajemen keberhasilan kelompok, adanya manajemen waktu untuk menyelesaikan proyek dengan baik, adanya pembagian tugas sesuai dengan kemampuan dan ketertarikan masing-masing siswa. Oflaz \& Turunc (2012) menyatakan bahwa adanya keberagaman gaya belajar dalam kelompok akan membantu siswa berkonsentrasi dan menunjukkan performa yang bagus terhadap tugas yang diberikan kelompok padanya. Selain itu, siswa 
juga menjadi lebih aktif selama proses pembelajaran.

\section{SIMPULAN DAN SARAN}

Hasil penelitian menunjukkan bahwa instrumen penilaian proyek yang dikembangkan valid dan reliabel. Instrumen penilaian proyek yang dikembangkan juga efektif digunakan dalam pembelajaran karena hasil nilai proyek dan nilai hasil belajar semua siswa minimal pada kriteria baik, serta adanya peningkatan $\mathrm{N}$-gain dengan kategori tinggi untuk siswa visual, siswa auditori, dan siswa kinesthetik.

\section{UCAPAN TERIMAKASIH}

Terimakasih yang sebesarbesarnya kami ucapkan kepada Dra. Saptorini, M.Pi, Dr. Endang Susilaningsih, M.S, dan Dra. Sri Wardani, M.Si sebagai validator instrumen penilaian.

\section{DAFTAR PUSTAKA}

Amalina, H., Sudarmin \& Latifah. 2013. Pengaruh Model Pembelajaran Quantum Teaching Berbantuan Modul Qt-Bilingual terhadap Hasil Belajar Siswa. Jurnal Inovasi Pendidikan Kimia, 7(2): 114557.

Andreea, L. \& Stancuna, O. 2014. A Multiple Intelligences Approach 2: Project-Based Assessment. Precedia-Social and Behavioral Sciences, 128: 504-08.

Holm, M. 2011. Project-Based Instruction: A Review of the Literature on Effectiveness in Prekindergarten through 12th
Grade Classrooms. Rivier Academic Journal, 7(2): 1-13.

Inayati, I., Subroto, T. \& Supardi, K.I. 2012. Pembelajaran Visualisasi, Auditori, Kinestetik Menggunakan Media Swismax Materi Larutan Elektrolit dan NonElektrolit. Chemistry in Education, 2(1).

Jagantara, I.M.W., Adnyana, P.B. \& Widiyanti, N.L.P.M. 2014. Pengaruh Model Pembelajaran Berbasis Proyek (Project Based Learning) Terhadap Hasil Belajar Biologi Ditinjau dari Gaya Belajar. e-Journal Program Pascasarjana Universitas Pendidikan Ganesha, 4.

Kunandar. 2013. Penilaian Autentik. Jakarta: RajaGrafindo Persada.

Kyprianidou, M., Demetriadis, S., Tsiatos, T. \& Pombostis, A. 2012. Group Formation Based on Learning Style: Can it Improve Students Teamwork? Education Technology Research Development, 60: 83-110.

Leopold, L. 2012. Prewriting Tasks for Auditory, Visual, and Kinesthetic Learners. Tesl Canada Journal, 29(2): p.102.

Lestari, R.A., Hadisaputro, S. \& Nusowati, M. 2015. Pembelajaran Berbasis Proyek dengan Produk Artikel untuk Meningkatkan Hasil Proyek. Chemistryin Education, 4(2). 
Lillyman, S., Gutteridge, R. \& Berridge, P. 2011. Using a Storyboarding Technique in the Classroom to Address End of Life Experiences in Practice and Engage Student Nurses in Deeper Reflection. Nurse Education in Practice, 11(3): 179-85.

Mulyasa, E. 2013. Pengembangan dan Implementasi Kurikulum 2013. Bandung: PT Remaja Rosdakarya.

Oflaz, M. \& Turunc, T. 2012. The effect of Learning Style on Group Work Activities. Procedia - Social and Behavioral Sciencies, 46: 1333-38.

Porter, B.D. \& Hernacki, M. 2008. Quantum Learning : Membiasakan Belajar Nyaman dan Menyenangkan. Bandung: Mizan Pustaka.

Safitri, E. 2015. Pengembangan Perangkat Activity-Based
Assessment (ABA) untuk

Mengukur Keterampilan

Proses Mahasiswa pada

Matakuliah Praktikum Fisika

Dasar II. Tesis. Semarang:

Universitas Negeri Semarang.

Sari, A.K. 2014. Analisis Karakteristik Gaya Belajar VAK (Visual, Auditorial, Kinestetik) Mahasiswa Pendidikan Informatika Angkatan 2014. Jurnal Ilmiah Edutic, 1(1): 1-12.

Schnittka, C.G., Evans, M.A., Won, S.G.L. \& Drape, T.A. 2015. After School Spaces: Looking for Learning in All the Right Places. Res Science Education.

Wijayanti, A. 2014. Pengembangan Authentic Assessment Berbasis Proyek dengan Pendekatan Saintifik untuk Meningkatkan Keterampilan Berpikir Ilmiah Mahasiswa. Jurnal Pendidikan IPA Indonesia, 3(2): 102-08. 